\title{
Pelas lentes do SUS: notas sobre desafios e avanços da promoção da saúde na atenção primária
}

\section{Through "SUS" lenses: notes on challenges and advances in health promotion in primary care}

\section{Por las lentes del "SUS": notas sobre desafíos y avances de la promoción de la salud en la atención primaria}

\author{
iD Marcos Bagrichevsky \\ Universidade Regional de Blumenau, Blumenau, Santa Catarina, Brasil
} e-mail: marcos_bagrichevsky@yahoo.com.br

\begin{abstract}
Resumo: Proponho um balanço crítico, retrospectivo e breve acerca de desafios e avanços de práticas e da política de promoção da saúde (PS), subjacentes ao SUS. A narrativa analítica partiu de textos científicos/ governamentais (selecionados por critério de conveniência) e de situações profissionais vivenciadas in loco em serviços da atenção primária (APS), nos últimos 15 anos. Defendo que as práticas de PS tiveram alguns avanços importantes na APS, materializados em experiências exitosas nos territórios/comunidades. Entretanto, a conjuntura sociossanitária profundamente desigual perpetuada no país e o cenário de retrocessos sociais instalado pelo atual governo federal transformam boa parte das metas e propostas da Política Nacional de PS em perspectivas inalcançáveis à maioria dos brasileiros.
\end{abstract}

Palavras-chave: Sistema Único de Saúde (SUS). Promoção da saúde. Política Nacional de Promoção da Saúde (PNPS). Atenção Primária à Saúde (APS).

Abstract: I propose a critical, retrospective, and brief assessment of the challenges and advances in health promotion (HP) practices and 
policy, underlying SUS. The analytical narrative started from scientific/ governmental texts (selected by convenience criteria) and professional situations experienced in loco in primary health care (PHC) services, in the last 15 years. I argue that the HP practices have had some important advances in PHC, materialized in successful experiences in the territories/ communities. However, the profoundly unequal socio-health situation perpetuated in the country, and the scenario of social setbacks installed by the current federal government, transform most of the goals and proposals of the National Health Promotion Policy into unattainable perspectives for most Brazilians.

Keywords: Brazilian Unified Health System. Health Promotion. National Health Promotion Policy. Primary Health Care.

Resumen: Propongo un balance crítico, retrospectivo y breve, acerca de desafíos y avances de prácticas y de la política de promoción de la salud (PS), subyacentes al SUS. La narrativa analítica partió de textos científicos/gubernamentales (seleccionados por criterio de conveniencia) y de situaciones profesionales vividas in loco en servicios de la atención primaria (APS), en los últimos 15 años. Defiendo que las prácticas de PS tuvieron algunos avances importantes en la APS, materializados en experiencias exitosas en los territorios/comunidades. Sin embargo, la coyuntura sociosanitaria profundamente desigual perpetuada en el país, y el escenario de retrocesos sociales instalado por el actual gobierno federal, transforman buena parte de las metas y propuestas de la Política Nacional de PS en perspectivas inalcanzables para la mayoría de los brasileños.

Palabras Clave: Sistema Único de Salud. Promoción de la Salud. Política Nacional de Promoción de la Salud. Atención Primaria de Salud.

Submetido em: 13-10-2020

Aceito em: 29-10-2020 
Pelas lentes do sus: notas sobre desafios e avanços da promoção da saúde... Marcos Bagrichevsky

\section{Pelas lentes do sus: notas sobre desafios e avanços da promoção da saúde na atenção primária}

O Sistema Único de Saúde (SUS) completou, recentemente, 30 anos de sua implantação. Indiscutivelmente, é a maior política social em curso no Brasil. A promoção da saúde (PS) se insere nesse contexto como um campo autoral, gerador de políticas e práticas diferenciadas, cuja 'ideia-força' não é nova. Seus pressupostos conceitual-programáticos remetem aos primórdios da Reforma Sanitária Brasileira e aos debates propostos ainda nos anos 1970 sobre uma 'visão ampliada de saúde'. Desde então, as vertentes críticas da PS têm desafiado gestores e profissionais da atenção primária à saúde (APS) a construir caminhos outros que viabilizem/ incorporem estratégias de cuidado sensíveis, guiadas pelos princípios da Integralidade e da Equidade e atentas às demandas populacionais nos territórios. Ao considerar alguns esboços do atual panorama sociossanitário do país e suas insuficiências (SOUZA et al., 2019; MACHADO; SILVA, 2019), busco examinar, muito resumidamente, percursos, desafios e dilemas da PS nesse cenário, bem como seus avanços mais recentes.

Pensar/intervir sobre o processo saúde-doença, interpretando seus múltiplos significados de maneira consequente - como fenômeno conectado aos acontecimentos econômicos, políticos, culturais da vida cotidiana -, representa uma tarefa complexa, sobretudo a partir de uma ótica interdisciplinar. Esse é um compromisso permanente das equipes multiprofissionais de saúde que compõem o "primeiro nível de cuidado" no SUS, também chamado de "porta de entrada do sistema" ou APS (TESSER; POLI NETO; CAMPOS, 2010).

O contexto dos territórios periféricos no Brasil, no qual atuam as equipes da APS, é a feição de lugares quase sempre eivados de iniquidades, violências e, historicamente, à margem do alcance de políticas públicas resolutivas. Falo de coisas básicas: (falta de) acesso à trabalho, renda, educação, moradia, alimentação, sanea- 
Pelas lentes do sus: notas sobre desafios e avanços da promoção da saúde... Marcos Bagrichevsky

mento dignos (MACHADO; SILVA, 2019). Por motivos óbvios, esse quadro precisa ser considerado, problematizado e incluído no continuum dos projetos terapêuticos ampliados de saúde que se destinam ao cuidado integral e equânime das pessoas/comunidades.

A incorporação desse conjunto de premissas pelos profissionais da APS constitui uma das diretrizes orientadoras do SUS. A adoção regular dessa práxis, no processo de trabalho das equipes da APS, demonstra, há algum tempo, ter implicações significativas no enfrentamento e mitigação dos problemas de saúde locorregionais (SOUZA et al., 2019).

Há consenso entre acadêmicos, profissionais, gestores e formuladores de políticas que o SUS alavancou a transformação do modelo assistencial em saúde no país. O desenvolvimento de uma cultura de 'outras práticas' na APS, sintonizadas com a dimensão do 'olhar ampliado' sobre o processo saúde-adoecimento, passou a conferir um protagonismo cada vez maior à promoção da saúde como campo indutor de 'modos diferenciados' de se pensar e realizar o cuidado nas experiências diárias dos serviços (SANTOS et al., 2006; POLIDORO; DA ROS, 2017; PINTO; SILVA, 2019; SANTOS; BALDISSERA; TOLEDO, 2019).

Correntes críticas de pensadores e sanitaristas brasileiros têm creditado à promoção da saúde potencial para tornar-se um valioso contraponto ao modelo biomédico hegemônico de assistência e à sua lógica medicalizante, postulando ainda que esse é um dos grandes desafios a ser encarado por profissionais e gestores que militam no campo público da saúde (FERREIRA NETO; ARAÚJO, 2014; CZERESNIA; FREITAS, 2017).

Para que os serviços consigam auferir ações de promoção da saúde adequadas às nossas micro-realidades conjunturais, é preciso atender e articular duas tarefas essenciais na rotina da APS: (i) refletir acerca dos pressupostos ético-políticos que guiam tais práticas; e (ii) considerar a necessidade de reconfiguração dos empreendimentos pedagógicos tradicionais, ainda dominantes nas atividades de 'educação em saúde' utilizadas junto aos gru- 
Pelas lentes do sus: notas sobre desafios e avanços da promoção da saúde... Marcos Bagrichevsky

pos comunitários (SANTOS et al., 2006; CZERESNIA; FREITAS, 2017; POLIDORO; DA ROS, 2017; PINTO; SILVA, 2019).

A perspectiva crítica de promoção da saúde, no Brasil, clama tanto por ações, programas e políticas - dentro e fora do setor saúde - para melhorar as condições estruturais da sociedade (SILVA; BAPTISTA, 2015; CZERESNIA; FREITAS, 2017) quanto pela abertura ao contexto da vida 'não medicalizada' (FERREIRA NETO; ARAÚjO, 2014), que requer uma produção contínua de estratégias para valorizar e viabilizar a escuta, o acolhimento, o vínculo e as singularidades dos sujeitos. E ambas as vertentes não se excluem mutuamente, é bom que se diga. Ao contrário, elas convergem e se somam na direção de um projeto politizador, socialmente relevante, mas sem a ingênua pretensão de tornar-se a 'salvação' para todos os 'males' que acometem nossas coletividades.

Em relação a essa segunda faceta, da desmedicalização e do respeito às subjetividades humanas, é imprescindível que o repertório de dispositivos empregados pelos profissionais da APS contemple/acate os aspectos que conferem sentido existencial às pessoas, às famílias, pois a primazia dos processos de cuidado integral em saúde diz respeito e se destina a elas. Suas prioridades e aspirações de vida não devem ser descartadas nem 'objetificadas', mesmo diante de situações extremas de adoecimento. Também os gestores do setor ocupam um papel estratégico nesse contexto (FERREIRA NETO; ARAÚJO, 2014) e precisam estar comprometidos com as mesmas orientações, desenvolvendo-as de forma cotidiana, pari passu com os serviços.

Os problemas estruturais da conjuntura brasileira são intrincados e numerosos. Eles requerem do campo da promoção da saúde (e daqueles que por ele transitam) a construção de propostas de cuidado alinhadas ao imperativo de combater as injustiças concretas da realidade cotidiana. Igualmente importante, é a necessidade de institucionalizar as iniciativas de promoção da saúde existentes (POLIDORO; DA ROS, 2017; PINTO; SILVA, 2019; SANTOS; BALDISSERA; TOLEDO, 2019), fazendo-as alcançar outro patamar de visibilidade pública e tornando-as mais prestigiadas/ 
Pelas lentes do sus: notas sobre desafios e avanços da promoção da saúde... Marcos Bagrichevsky

reconhecidas nos serviços, assim como os profissionais que planejam e conduzem esses processos.

Nesse sentido, levanto uma questão endereçada àqueles que ocupam cargos na formulação de políticas e na gestão dos serviços de saúde em nosso país: por que não conceder aos trabalhadores de saúde responsáveis pelos grupos/projetos de promoção da saúde (SANTOS et al., 2006) nos territórios da APS, as mesmas "premiações em dinheiro"1 destinadas formalmente às equipes de saúde que obtêm redução de indicadores epidemiológicos de morbimortalidade? Em linhas gerais, as propostas estruturadas de promoção da saúde são duradouras, obtêm adesão longeva dos frequentadores de grupos/projetos, promovem vínculo, criam espaços de escuta, de sociabilidades e de politização nas comunidades. Dito de outro modo, sobram motivos concretos e plausíveis para que sejam reconhecidas e 'oficializadas' pelas instâncias administrativas das secretarias de saúde dos municípios brasileiros, como ações potentes e resolutivas. Apesar de caracterizar-se como uma reivindicação antiga de profissionais que atuam com promoção da saúde na APS, o questionamento aqui levantado expressa também um dilema recorrente do qual os gestores não conseguem se desvencilhar: como definir escolhas adequadas (conceituais e metodológicas) para o enfrentamento de distintos problemas de saúde presentes nas comunidades, sem que na balança da 'objetividade versus subjetividade' apenas a primeira oriente majoritariamente as tomadas de decisão?

Mas, a despeito da existência de problemas ético-políticos como o destacado, de forma breve, no texto (que merece ser discutido em profundidade!), vale dizer que acumulamos na última década e meia inúmeras experiências exitosas de promoção da saúde conduzidas por equipes de saúde em toda a extensão territorial do Brasil (SANTOS et al., 2006; POLIDORO; DA ROS, 2017; PINTO; SILVA, 2019; SANTOS; BALDISSERA; TOLEDO, 2019). O re-

\footnotetext{
1 No SUS, existe, desde 2011, um programa chamado PMAQ-AB (Programa de Melhoria do Acesso e da Qualidade da Atenção Básica), que paga gratificações em dinheiro aos profissionais/equipes de saúde da APS que alcançam "metas de produtividade" em relação à melhoria de indicadores epidemiológicos preconizada pelo Ministério da Saúde. A crítica recorrente é que não há nada similar proposto para "valorizar do mesmo modo" os profissionais que trabalham de forma contínua com ações/grupos de promoção da saúde e/ou com as dimensões subjetivas do cuidado e que, sabidamente, também têm êxito através dos seus respectivos "projetos terapêuticos ampliados".
} 
Pelas lentes do sus: notas sobre desafios e avanços da promoção da saúde... Marcos Bagrichevsky

gistro de sua crescente presença nos territórios da APS sinaliza dois aspectos: (i) o quanto as intervenções de promoção da saúde podem contribuir para o bem-estar das populações locais e mitigar as dificuldades que atravessam e impedem o cuidado pleno, contínuo; e (ii) que alcançamos um status interessante rumo à consolidação de um modelo de assistência à saúde preconizado e desejado para o SUS (SOUZA et al., 2019; MACHADO; SILVA, 2019).

\section{As abordagens de promoção da saúde contra-hegemôni-} cas encontradas nos territórios da APS têm como diretriz primeira a dimensão ética da vida dos sujeitos e das coletividades (SANTOS et al. 2006; POLIDORO; DA ROS, 2017; PINTO; SILVA, 2019; SANTOS; BALDISSERA; TOLEDO, 2019). Elas trazem consigo conceitos imprescindíveis ao cuidado em saúde que pressupõem capacidade de interlocução entre diferentes saberes e práticas. Tal compreensão demanda dos atores do setor muito mais do que o uso de ferramentas para mapear problemas sanitários; deles se espera uma análise interdisciplinar interpretativa que também busque considerar a complexidade do processo saúde-doença e todos os modos de subjetivação que ele mobiliza; que se desprenda de significações mais imediatas (aquelas tradicionalmente esperadas pelo modelo biomédico) e que seja capaz de expressar um quadro mais detalhado, sensível e profundo que cada conjuntura examinada exige.

O balanço final que faço da perspectiva contemporânea da PS no Brasil aponta percursos densos e trilhados sob intensas disputas, ainda em curso. São transformações recentes, é bem verdade, mas dignas de nota! O permanente debate em torno da Política Nacional de Promoção da Saúde (PNPS), evocado por diferentes atores da sociedade, e as repercussões daí decorrentes ilustram meu ponto de vista: publicada inicialmente em 2006, a PNPS passou por sua segunda revisão em 2014, exibindo, desde então, mudanças textuais expressivas em teor e número (SILVA; BAPTISTA, 2015). Uma dessas alterações, inclusive, reconheceu, só oito anos depois, o papel dos modos de subjetivação na composição dos 
Pelas lentes do sus: notas sobre desafios e avanços da promoção da saúde... Marcos Bagrichevsky

projetos terapêuticos de cuidado - já que tal preocupação inexistia na primeira versão oficial da PNPS (publicada em 2006).

Ainda há muito por fazer, pelo que lutar, nas políticas e nos serviços de saúde. Todavia, mesmo diante do atual panorama calamitoso no país, a ostentar retrocessos sociais imensuráveis que causam perplexidade até ao cenário internacional, nesses tempos de pandemia, temos avanços na trajetória da PS impulsionados pelo SUS, que merecem nosso reconhecimento e que precisam ser assinalados!

Vida longa ao SUS, patrimônio de toda a população brasileira, pobres ou ricos, com ou sem trabalho formal, e até mesmo daqueles que não o defendem!

\section{Referências}

CZERESNIA, D.; FREITAS, C. M. (Orgs). Promoção da saúde: conceitos, reflexões, tendências. 2 ed. Rio de Janeiro: Fiocruz, 2017. FERREIRA NETO, J. L.; ARAÚJO, J. N. G. Gestão e subjetividade no SUS: o enfrentamento de impasses em tempos neoliberais.

Psicologia e Sociedade, São Paulo, v. 26, n. 3, p. 675-684, 2014. https://doi.org/10.1590/S0102-71822014000300016

MACHADO, C.V.; SILVA, G. A. Political struggles for a universal health system in Brazil: successes and limits in the reduction of inequalities. Globalization and Health, London, v. 15, suppl. 1, 77, 2019. https://doi.org/10.1186/s12992-019-0523-5

PINTO, M. B.; SILVA, K. L. Promoção da saúde no território: potências e desafios dos projetos locais. Escola Anna Nery, Rio de Janeiro, v. 23, n. 1, e20180282, 2019. https://doi.org/10.1590/ 2177-9465-ean-2018-0282

POLIDORO, A. A.; DA ROS, M. A. Roda de chimarrão como instrumento promotor de saúde na realização da atenção básica: um artefato cultural, ético e político. Saúde \& Transformação Social, Florianópolis, v. 8, n. 2, p. 26-38, 2017. 
Pelas lentes do sus: notas sobre desafios e avanços da promoção da saúde... Marcos Bagrichevsky

SANTOS, F. N. P., BALDISSERA, V. D. A.; TOLEDO, R. F. Conversa de Boteco: participação, educação e promoção da saúde do homem. Escola Anna Nery, Rio de Janeiro, v. 23, n. 3, e20190006, 2019. http://dx.doi.org/10.1590/2177-9465-ean-2019-0006

SANTOS, L. M. et al. Grupos de promoção à saúde no desenvolvimento da autonomia, condições de vida e saúde. Revista de Saúde Pública, São Paulo, v. 40, n. 2, p. 346-352, 2006. https:// doi.org/10.1590/S0034-89102006000200024

SILVA, P. F.A.; BAPTISTA, T. W. F. A Política Nacional de Promoção da Saúde: texto e contexto de uma política. Saúde em Debate, Rio de Janeiro, v. 39, supl. 1, p. 91-104, 2015. https://doi.org/10.5935/0103-1104.2015S005327

SOUZA, L.E.P.F. et al. Os desafios atuais da luta pelo direito universal à saúde no Brasil. Ciência \& Saúde Coletiva, Rio de Janeiro, v. 24, n. 8, p. 2783-2792, 2019. https://doi. org/10.1590/1413-81232018248.34462018 TESSER, C. D.; POLI NETO, P.; CAMPOS, G. W. S. Acolhimento e (des)medicalização social: um desafio para as equipes de saúde da família. Ciência \& Saúde Coletiva, Rio de Janeiro, v. 15, supl. 3, p. 3615-3624, 2010. https://doi.org/10.1590/S141381232010000900036

\section{Publisher}

Universidade Federal de Goiás. Faculdade de Educação Física e Dança. Publicação no Portal de Periódicos UFG. As ideias expressadas neste artigo são de responsabilidade de seus autores, não representando, necessariamente, a opinião dos editores ou da universidade. 